\title{
Breaking Down Rhetorical Relations for the purpose of Analysing Discourse Structures
}

\author{
Jun'ichi FUKUMOTO* Jun'ichi 'TSUJII † \\ Centre for Computational Linguistics, UMIST \\ P.O.Box 88, Manchester M60 1(2I), United Kingdom \\ E-mail jun@ccl.umist.ac.uk isuji@ecl.umist.ac.uk $\downarrow$
}

\begin{abstract}
In Rhetorical Structure 'l'heory (RST') the definitions of some relations are rather vague because they are given on a pragnalic basis. 'This paper presents another way of seeing the relations which leads to a more precise specification of the relations. The relations are associated with constraints on the semantic relationships between the propositional contents of two clauses, their Modality and Tense/Aspect.
\end{abstract}

\section{Introduction}

'The Rhetorical Structure 'Theory (RST') by Mann and 'Thompson [Mann and 'Thompson, 1987] is a theory of inter-sentential (or inter-clausal) relationships in a text. Although RS'I' is intended to serve both as a francwork for text analysis and text generation, it has so far been used exclusively in text generation [Hovy ct al., 1992] [Lindon et al., 1992] [Rösiner and Stede, 1992]. Several researchers recognise that RST has defects as an analytical framework. Moore and Pollack [Moore and Pollack, 1992], for example, claim that the assumption of a single relation between discourse elements is one of the reasons why RS' analyses ase inherently antbiguous. They also claim that the underspecificity of the rhetorical relation definitions causes problems.

Our claim is that the main cause of the clifliculties of applying RST to text processing systems is that some of the relations are defined on the basis of the eflects which they have on a reader. 'This is particularly the case for the relations classified as presentational relalions, the relations whose intended effects are to increase some inclination in a reader.

Background rolation, for example, is defined as a relation whose Satcellite increases the ability of a reacler to comprehend an elemont in Nucleus and the reader will not fully comprehend Nucleus before reading the text of Satellite. 'l'his definition is problematic because there are many ways of increasing the ability of a reader to comprehend Nucleus. More seriously, the definition

\footnotetext{
*Supported by Oki Blectric Industry Go, Mad.
}

itself does not predict, anything about textual forms of Nucleus and Satellite.

In order to use RS'T in actual text processing systems, we have to break down such definitions to relate them with textual forms. In this paper, we show how the definitions can be broken down and be associated with semantic constraints betwen constituents (clauses), in order to relate them with constraints on surface linguistic forms. Among the 24 rhetorical relations defined in [Mann and 'I'hompson, 1987], we locus on presentational relations ( 7 relations are classified as such) which are the most problematic. 'T'he results of applying our method to leading articles in a $J$ apancse newspaper are also discussed.

\section{Basic Framework}

In RS'I, 24 relations are divided into two groups: presentational relations and subject maller relations. According to Manm and 'Thompson [Mann and 'Thompson, 1987], subject matter relations are those whose intended effect is that the reador recognises the relation in question and presentational relations are those whose intended eflect is to increase some inclination in the reader. Moore and Pollack [Moore and Pollack, 1992] comment that subject matter relations are informalional and presentational relations are intentional.

Table 1 shows what kind of inclination each presenttational relation is intended to increase. One can sec that the definitions are highly abstract and have nothing to do with the surface realisations of the relations.

On the other hand, it has been observed that there are various surface cues in texts which are useful for idcntifying inter-sentential (or inter-clausal) muits. Halliday and IIasan [Halliclay and Ilasan, 1985] identified a set of linguistic devices for linking one part of a text to another, such as reference, substitution and cllipsis, conjunction, and lexical cohesion.

From the view point of text processing, these lingruistic devices can be used as cues for segmenting a text into structural units (Satellite and Nucleus). Ilowever, these cues hardly give any clue about which clause of a unit is Satellite, which clause is Nucleus, and which 
Table 1: RS rolations and their inclination type

\begin{tabular}{l|l}
\multicolumn{1}{c|}{ relation } & \multicolumn{1}{|c}{ kind of inclination } \\
\hline Background & ability of R to comprehend an element \\
Enablement & potential ability to perform action in \\
Motivation & $\mathrm{N}$ \\
resire to perform action in $\mathrm{N}$ \\
Didence & belief of $\mathrm{N}$ \\
Justify & readiness lo accept writer's right in $\mathrm{N}$ \\
Antitlicsis & $\begin{array}{l}\text { positive regard for situation presented } \\
\text { in } \mathrm{N} \\
\text { positive regard for situation presented } \\
\text { in } \mathrm{N}\end{array}$ \\
Concession
\end{tabular}

RS relation combines the two clauses into a single unit. For determining these, we have to look for other kinds of surface cues.

Because RS relations are defined pragmatically, their ultimate recognition requires understanding of texts which in turn requires detailed knowledge about the world. Furthermore, the condition that the presentational relations are inherently intentional, implies that their recognition requires knowledge about the writer's intention, plans, etc. Because this kind of information is intplicit in texts, its recognition often causes problenis.

However, thongh the writer's intention is implicit, certain linguistic clevices give us clues to infer it. Modality information in a clause, for example, cxpresses the writer's attitude loward an event/state closcribed, and thercfore, often gives us clues to recognise a RS relation.

Let us consider the following two examples:

[Example 1]

(1) I prepared documents for a meeting.

(2) I sent them to the head office.

[Example 2]

(1)' I am preparing documents for a meeting.

(2)' I have to send them to the head oflice.

Though these two examples clescribe pairs of similar cvents, the relation between (1) and (2) in Example 1 is (temporal) Sequence (a subject matter relation) because they simply describe two events which happened in sequence. On the other hand, in Example 2, (1)' describes an event occurring simultaneously with the utterance, and (2)' concerns what the writer plans to do. While the two events, preparing documents and sending them, may happen in this sequence, the relation is not regarded as Sequence but as Background. (2)' gives the reason why the writer is performing the action described by $(1)^{\prime}$

This change of RS relation occurs due to the difference of modality of (2) and (2)'. Our basic claim is that, though they cannot determine RS relations uniquely, information of modality and tense of clauses imposes significant constraints on possible RS relations, and, being used together with other surface cues like clausal conjunctions, it can reasonably restrict a set of possible discourse structures of texts without resorting to detailed knowledge about the world and the writer's plan.

Ilowever, the contribution of modality and tense to the constraints of RS relations is not straightforward. Both these grammatical features are intertwincel with the propositional content of clauses. Therefore, in order to formulate the constraints on then properly, we have first to reveal how the intended effects of RS jelations can be attained. This leads to our breaking down single RS relations into sets of subschemas, each of which is formulated in terms of the sonantic relationships between propositional contents of clauses, their nodality and temporal relationships.

\section{Properties of Clauses}

Like Mann and Thompson, we use clanses as the basic constituents which are related by RS relations, except that clausal subjects and complements and restrictive relative clauses are considered parts of thejr host clause. The constraints which we formulate for each RS relation are expressed in terms of properties of clauses. In order to express these constraintis formally, wo first introduce the basic terms.

\subsection{Contents and Modality}

$\Lambda$ clause comprises its Contents and Modality. Modality is the part which expresses the writer's attitude toward the Contents.

While individual langnages have their own linguistic devices or grammatical forms of modality, what sortis of modality are expressed by such linguistic devices does not, vary from one language to another. For example, although the major linguistic clevice for modality are modal auxiliary verbs both in linglish and in Japanese, some kinds of modality expressed in Japanese by nodal auxiliary verbs are expressed by lexical verbs in Finglish, and vice versa. ${ }^{1}$

Eurthermore, we find many phrasal or quasi-phrasal expressions which consist of several words, and which collectively express the writer's altitude toward the event/state described. In order to treat then, we adopt a semantics-based view for the delinition of Modality. That is, we treat expressions which conceru the writer's attitude as modal expressions, whichever linguistic forms they may take. We tirst cstablish a classification sclema of Modality based on semantic considerations (Sce Section 3.3) and then treat all expressions whose functions can be classified under this schema as modal expressions.

\footnotetext{
The concepts expressed by Jinglish lexical verbs like wish, hope, beg, urge, etc, for example, are often expressed by modal auxiliaries in Japanese, when the subject is the writer or speaker.
} 
Contents of a clause is delined as the part which remains after removal of the modal expression. Contents contain expressions concerning tense and aspect, which also contribute to the specification of constraints on RS relations. The sante discussion as the above can be applied to 'Tense and Aspect, so that all expressions whose function is to express temporal aspects of clauses are, regardlessly of their actual forms, treated in the same classification schentas. T'ense/Aspect are represented as properties of (Contents (See Section 3.2)

\subsection{Properties of Contents}

Contents is the main part of Clause of which a truth value can be established. Contents is characterised by three attributes: Type, Time and guality.

\section{(a) Typo}

The truth value of Contents changes according to the time axis. We can think of two time points, $t_{b}$ and $t_{b}$, where the Contents $C$ is true during the time interval between $t_{a}$ and $t_{b}$. Depending on the temporal nature, we classify Contents into the following four classes.

$$
\begin{aligned}
& \text { - Silatic } \\
& t_{t}=\text { undel', } t_{b}=\text { undef, } C(t)=\text { true } \\
& \left(t_{a}<t<t_{b}\right) \\
& \text { - Duretive } \\
& t_{a t}=\text { def, } t_{b}=\operatorname{de}[, C(t)=\operatorname{truc} \\
& \left(t_{a}<t<t_{b}\right) \\
& \text { - Repelitive } \\
& l_{a}=\text { def, } t_{b}=\operatorname{def}\left(C\left(t_{i}\right)=\right.\text { true } \\
& \left(t_{a}<t_{1}<t_{2}<\cdots t_{i}<\cdots<t_{n}<t_{b}\right) \\
& \text { - Non-repelilive } \\
& t_{b}=\text { def, } t_{b}=\operatorname{def}, c\left(t_{i}\right)=\text { true } \\
& \left(i=1 ; t_{a} \leq t_{i} \leq t_{b} ; t_{a} \doteq t_{b}\right)
\end{aligned}
$$

In the above, $l_{a / b}=$ undef in static means that the t,ruth value of Contents does not change.

\section{(b) Time}

The temporal nature of Contents is also chassified in terms of the speech time, $T S$, as follows.

$$
\begin{array}{ll}
\text { - Before } & : T_{s}<t_{a} \\
\text { - Simullancous } & : t_{a}<T_{S}<t_{b} \\
\text { - After } & : t_{b}<T_{s}
\end{array}
$$

We ne the following notation to specily a temporal relationship between two Contents $\left(C_{1}\right.$ and $\left.C_{2}\right)$.

$$
\begin{array}{lll}
C_{1} \ll C_{2} & \ldots & C_{1} \text { occurs betore } C_{2} \\
C_{1} \gg C_{2} & \cdots & C_{1} \text { occurs after } C_{2}
\end{array}
$$

\section{(c) Quality}

Contents is also classified according to whether the writer believes it is good or bad. 'Jhis classifica- tion is represented by the attribute Quality (tty) whose value is either good or bad. ${ }^{2}$

\subsection{Properties of Modality}

Concerning morlality, a number of criteria have been proposed. Pahmer [1'almer, 1986] took the same. semantics-based view of Modality as we discussed in Section 3.1, though he hardly extended his analysis to cover plurasal or quasi-phrasal expressions. Wo adopt his classification schema and modify it. He classilied modality into Epistcmic modality and Deontic modal. $i t y$. Fistemic Modality is concerned with language as information, will the experession of the degree or na ture of the writer's commitment, to the truth of what $\mathrm{s} /$ he says. Deontic modality is concened with lauguage as action, mostly with the expression by the writer of his/her attitude towareds possible actions by him/herself and others.

\subsubsection{Fpistemic modality}

Epistenic modality is classilied according to the tegree of the writer's commitment to the truth of Contents, as follows.

- Hividential (M-ept:vi

The truth condition of (ontents is based on ovidence like sensory evidence or linguistic evidence.

- Confidential (M-cp con $)$

The truth condition of Contents is based on the degree of confidence expressed by the writer.

- Inferential (M-epinf $)$

The truth condition of Contents is based on a reatsoning rule of the writer and inferred from the other facts.

- Assumplive (M-epann)

'The truth condition of Contents is based on some assiunption.

'The degree of the writer's commitment to the truth becomes weaker in the order of lividential, Confidential, Inferential, Assumptive. In the following sections,

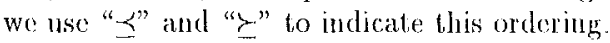

$$
C_{x} \succeq C_{y} \quad \text { or } \quad C_{y} \preceq C_{x}
$$

means that the degree of the writer's commitment to the truth of Contents $C_{x}$ is higher than or equal to the degree of the writer's commitment to the truth of Contents $C_{y}$.

\footnotetext{
${ }^{2}$ When the writer does not, think that his/her judgenent is obvious for reaclers, s/he ustally expresses the julgement hy Modality. 'llherefore, this attribute has a value only when the juclgement can be marle hased on common sense knowledge.
} 


\subsubsection{Deontic modality}

Deontic modality is classified according to the kind of a writer's attitude which s/he expresses.

- Evaluative (M-de eva+, M-de eva- $)$ Evaluative expresses the writer's at titude towards what $s /$ he already accepts as true in his/her mind. There are two kinds of attitude; positive (' + ') and negative ('-').

- Volitive (M-denor+, M-de $e_{v o l-}$ )

Volitive is concerned with a possible action or situation which a writer is hoping or wishing to occur. There are two kinds of attitude; possible ('t') and impossible ('-').

- Directive (M-dedir)

Directive is concerned with an action which a writer tries to get others to perform. Though Directive is further classified into Permission and Obligation, their distinction is not relevant for our purpose.

- Commissive (M-rle com $)$

Commissive is concerned with all action which a writer commits him/herself to perform or to ensure that an event takes place.

- Request (M-de $\left.e_{\gamma^{\prime} \ell q}\right)$

Request is concerned with an action which a writer can ask others to do.

\subsubsection{Combination of Epistemic and Deontic modality}

In Deontic modality Evaluative and Volitive are concerned with a writer's attitude toward Contents which has a truth value. Therefore, clauses with these modalities can also have Epistemic modality. If a clause has any of the other values of Deontic modality like Directive, etic., the Clause has no Epistemic modality as such. However, for the simplicity of formulation in Section 4 , we assume their lepistemic modality value to be Confidential. ${ }^{3}$

\section{Breaking Down of Rhetorical Relations}

In this section, we will show how Backgronnd, Enablement, Motivation and Bvidence of the presentational relations are broken down into subschemas, and give formal representations of their constraints. The constraints comprise

(a) Semantic Relationships between Contents of the two clauses

\section{(b) Constraints on Time}

${ }^{3}$ This is not inappropriate because it is considered that a writer commits the action in the Clause with full confidence in his/her action. (c) Constraints on Modality.

(b) and (c) are expressed by using a characterisation of clauses of Section 3. We first show the framework for (a) and then give the actual breakclown of presentational relations.

\subsection{Semantic Relations}

By semantic relationships betwcen Contents we mean the relationships between states/actions/evonts described by Contents in the extra-linguistic world. ${ }^{4}$ As we see in Example 1 and 2, even when two actions seem to stand in the same semantic relationship, they can be used to attain different effects on a reader by adding different expression of a writer's attitude as Modality or putting them in different temporal relationships.

We classify semantic relationships into five categories, four of which also are subject matter relations in RSI'. That is, if two Contents are presented without, any Modality, they stand in the corresponding subject matter relations. We use the following symbols in their definitions.

$\mathrm{Cl}_{i}$ : Clause $i$ composed of Contents and Modality

$C_{i}$ : Contents of Clause $i$

$S_{i}$ : Contents of Clause $i$ whose Type is Static

$A_{i}$ : Contents of Clause $i$ whose Type is not Static

$M_{i}$ : Modality in Clause $i$

[Semantic Relations]

- $S_{i}-\left(A_{k}\right) \rightarrow S_{j}$ $A_{k}$ causes a situation change from $S_{i}$ to $S_{j}$. If a Contents states that $A_{k}$ causes a situation $S_{j}, S_{i}$ will be omiticd.

- $S_{i} \vDash=C l_{j}$ $C l_{j}$ is held true or acceptable in the cnviromment stated in $S_{i}$. If $C l_{j}$ expresses a situation, this relation is the same as Circumstance.

- $S_{i} \vdash C l_{j}$ $C l_{j}$ is held true or acceptable, if $S_{i}$ is true. If $C l_{j}$ expresses an action caused by $S_{i}$, this relation is the same as Cause and Result.

- $S_{i} \leadsto A_{j}$ $S_{i}$ has the possibility to resolve the problem stated in $A_{j}$. This relation is the same as Solutionhood.

- $C_{i} \Rightarrow C_{j}$ $C_{i}$ presents additional details about $C_{j}$ or is inferentially accessible in $C_{j}$ in one or more ways. This relation is the same as Elaboration.

\footnotetext{
${ }^{4}$ One may argue that such relationships have to be called pragtratic. However, we adopt a rather narow defuition of the term pragmatic and a broad definition of the term semantic. We use pragnatic only when it concerns effects on readers or the intention of the writer. The rest, like relationships held in the extra-linguistic world, are called semantic issues.
} 


\subsection{Subschemas of Presentational Re- lations in RST.}

We show breakdowns of four typical presentational relations into their subschemass and state their constraints more formally. The subscripts of " $u u^{\text {" and }}$ "sa" means Nucleus and Satellite, respectively.

\subsubsection{Background}

1. Time and space situations are stated by an action in Satellite, and uncler these situations an action in Nucleus becotues possible.

(a) $S_{0}-\left(A_{s a}\right) \rightarrow S_{1}, S_{1} \mid=A_{n u}$

(b) $A_{s, l} \ll A_{n n}$

$\left(A_{\text {nu }}\right.$ becomes true white $S_{1}$ is virue. Then, the time of $A_{s u}$ is betore $A_{n u}$.)

(c) $A_{s u} \succeq A_{n u}, M_{s u} \in\left\{\mathrm{M}-e p_{e n i|\operatorname{con}| i n f \mid c s, m}\right\}$ (If $A_{3 a}$ becomes possible in the environment given by $A_{s a}$, then the nodality of $A_{s a}$ should be more certain than that of $A_{n u}$.)

2. 'I'me and space situation are stated in Satcellite, and under the situation an action in Nucleus becomes possible.
(a) $S_{s u} \vDash A_{n u}$
(b) $S_{s a} \ll A_{n u}$
(c) $S_{s u}^{\prime} \succeq A_{n u} M_{s u} \in\{M-c p$ peni|cun|inf|usm\}

3. Satellite presents additional information to understiand Contents in Nucleus.

(a) $C_{s a} \rightarrow C_{n u}$

(b) $n o$

(c) $M_{s a} \in\left\{M-e p_{e v i|c o n| i n f \mid u s m}\right\}$,

$M_{n b u} \in\left\{\mathrm{M}-c p_{e v i|c o m| i n f \mid a s m}\right\}$

(Both Clauses will be understood as true, so they have to have truth value.)

4. An action in Nucleus has the possibility to resolve an undesirable situation which is caused by an ac-. tion in Satellite.

(a) $S_{i}-\left(A_{s a}\right)+S_{1}[q l y: b a d], A_{z u} \leadsto S_{1}$

(b) $A_{s a} \ll A_{n u}$

(c) $M_{s a} \in\left\{\mathrm{M}-c p_{i: v i \mid c o n}\right\}$

( $A_{s a}$ is an event which has occured or is occorring, or a writer is confident about the event. $\Lambda$ writer intends to do $A_{n n}$ to resolve a problem caused $A_{s a}$ )

5. Nucleus states an unclesirable situation cansed by another undesirable situation stated in Satellite.

(a) $S_{s a}[q l y: b a d] \vdash S_{m u}[q l y: b a d]$

(b) $S_{s a} \ll S_{n u}$

$$
\begin{aligned}
\text { (c) } S_{s a} \succeq S_{n u}^{\prime}, M_{s a} \in\left\{\mathrm{M}-c p_{e v i|c o n| i n f \mid a s m}\right\}, \\
M_{n u} \in\left\{\mathrm{M}-e p_{e v i|c o n|} \mid \text { inf } f \mid a s m\right\}
\end{aligned}
$$

6. An action in Nuckens can resolve an nndesirable situation stated in Satellite.
(a) $S_{s a}[q t y: b a d]-\left(A_{n u}\right) \rightarrow S_{1}[q t y:$ good $]$
(b) $S_{s a} \ll S_{u n u}$
(c) $M_{s a} \in\left\{\mathrm{M}-c p_{e v i|c o n| i n f \mid a s m}\right\}$

7. An action in Nucleus is caused by a situation in Satellite.

$$
\begin{aligned}
& \text { (a) } S_{s a}+A_{n u} \\
& \text { (b) } S_{s u} \ll A_{n u} \\
& \text { (c) } S_{s a} \succeq A_{n u l}, M_{s a} \in\left\{\mathrm{M}-c_{1} p_{\text {evi }|c o n| i n f \mid a s m}\right\} \text {, } \\
& M_{n u} \in\left\{\mathrm{M}-\left(p_{e, 1 /|\mathrm{rom}| i n f \mid u s m}\right\}\right.
\end{aligned}
$$

8. Based on a situation which is caused by an action in Satellite, a writer's attitude stated in Nucleus is accoptable.
(a) $S_{s a}^{\prime}=C l_{n u} \quad$ or $\quad S_{s u} F C l_{n u}$
(b) 110
(c) $S_{s a} \succeq S_{u t l}, M_{s a t} \in\left\{M-c p p_{c v i|c o n| i n f \mid a s m\}}\right\}$, $M_{n u} \in\left\{\mathrm{M}-d c_{e t) a|w o r| d i r|c o n n| r \in q}\right\}$

9. Hased on a judgencul stated in Salellite, it writer's attitude stated in Nuclens is acceptable?
(a) $C l_{s a}=C l_{n u} \quad$ or $\quad C l_{s a}+C l_{n u}$
(b) no
(c) $M_{s a} \in\left\{\mathrm{M} \cdots d e_{\text {fua }}\right\}$ $M_{n u} \in\left\{\mathrm{M}-d e_{\text {evict|uoldir|com|req }}\right\}$

\subsubsection{Lnablement}

1. Nucleus states an action which will be performed by a reader, and the action becomes possible by presenting the situalion in Satellite.
(a) $s_{s a}+A_{n u}$
(b) $s_{s a} \ll A_{n u}$

(When $S_{s / l}$ is presented, $A_{n u}$ becones possible. So, the time of $S_{s a}$ is before $A_{n u}$.)

(c) $M_{s a} \in\left\{\mathrm{M}-c p_{e n \mid c m n}\right\}, M_{n u} \in\left\{\mathrm{M}-d c_{d i v \mid r q q}\right\}$

$\left(S_{s a}\right.$ already exists or will exist, so $S_{s a}$ has the possibility to have truth value. If $S_{s a}$ is true, $A_{n u}$ beconces possible. So, s. sa should be more certain than $A_{n . \ldots}$.)

2. Nucleus states an action which will be perforned by a reader, and the action becomes possible by presenting the situation which is caused by an action in Saticllite.

(a) $S_{0}-\left(A_{s a}\right)+S_{1}, S_{1} \vdash A_{n u}$

(b) $A_{s i l} \ll A_{n u}$

(c) $M_{s a} \in\left\{\mathrm{M}-e p_{f v i \mid c o n}\right\}, M_{n u} \in\left\{\mathrm{M}-d c_{c} d r \mid r e q\right\}$ 


\subsubsection{Motivation}

1. An action stated in Nucleus causes a good situation stated in Satellite. It is considered that the situation motivates the reader to perform the action.
(a) $S_{0}-\left(A_{n u}\right) \rightarrow S_{s a}, S_{s a}[q t y: g o o d]$, actor $\left(A_{n u}\right.$, Reader $)$
(b) $A_{n u} \ll S_{s a}$
(c) $M_{s a} \in\left\{\mathbf{M}-e p_{c o n \mid} \mid\right.$ inf $\left.\mid a s m\right\}$, $M_{n u} \in\left\{\mathrm{M}-d e_{\text {eva|vol|dir|com|req }}\right\}$

2. An action stated in Nucleus causes a bad situation stated in Satellite. It is considered that the situation motivates the reader not to perform the action.
(a) $S_{0}-\left(A_{n u t}\right) \nrightarrow S_{s a}, S_{s a t}[q t y: b a d]$, $\operatorname{actor}\left(A_{n u}\right.$, Reader $)$
(b) $A_{n u} \ll S_{s q}$
(c) $M_{s a} \in\left\{\mathrm{M}-e p_{c o n|i n f|} \mid t s m\right\}$,
$M_{n u} \in\left\{\mathrm{M}-d e_{e v a \mid \text { ur|dir|com|req }}\right\}$

3. Satcllite states some attributive information related to an action in Nucleus, and the information way be desirable for Reader.
(a) $S_{s a}^{+}[q t y: g \circ o d] \Rightarrow A_{n u}$
(b) no
(c) $M_{s a} \in\{$ M-epr.vi|con|inf|asm $\}$

\subsubsection{Evidence}
(a) $C_{s a t} \vdash C_{n u}$
(b) $C_{s a} \ll C_{n u t}$
(c) $M_{s i b} \in\left\{M-e p_{e v i}\right\}, M_{n u} \in\left\{M-e p_{c o n \mid i n f}\right\}$

\section{Examples}

We will show an example of a text structure analysis. Figure 1 shows a sample text from a leading article in a Japanese newspaper ${ }^{56}$ and Table 2 shows the attributes of each sentence. The discourse structure of the sample text is shown in rigure 2.

In this example, the following relations are analysed as presentational relations. The number attached to a rolation nane shows the subschema number of the relation.

- Background(8) between '1-2' and ' 3 '

Sentence 3 has Evaluative modality about the sitnation ' 3 ' (economic crisis) and it is based on the situation of '1-2' (drop of dollar). 'These satisfy the constraints of the 8th subschema of Background.

\footnotetext{
${ }^{5}$ This article appeared in the October 30th, 1987, morning
} edition of the Asshi Shimbun.

${ }^{6}$ Literal translations are muade by the authors.
1 世界的な株式市場の混乱は外国為替市場にも波及し、 (A world-wide confusion in stock market affected the foreign exchange rate, )

2 ドル相埸が急落した。 (and exchange rates for the dollar dropped sharply.)

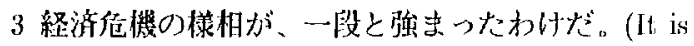
regarded that the aspect of economic crisis las been worsened.)

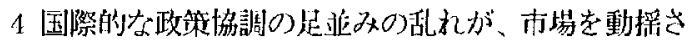
せている。(Disagreement of international policy is making the market unsetitle.)

5 ドルを䏚衛才るために (10 protect the dollar)

6 米国は、きぜんとした態影を示可べきときだ。(It is high time that US should show a resolute attitude.)

7 ドルは依然として基軸通貨の地位にあり、(The dollar is the key currency,)

8 もし米国が行き詰昰れば、(if US comes to a deadlock,)

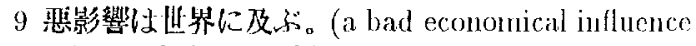
affects all the world.)

10 他の国ぐにも、この点走頭に入机て協調体制を目

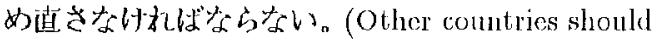
re-solidify their cooperation taking this point into consideration.)

(c)1987 Asahi Shimbun)

Figure 1: Sample text

- Background(6) between ' 4 ' and ' 5 -6'

'The semantic relation is that a bad situation in sentence '4' (unsettle market) will be rosolved by performing an action in ' $5-6$ ' (show a resolute attitude). Sentence ' $5-6$ ' has Directive modality. These satisfy the constraints of the 6th subschema of Background.

- Background(7) between ' 7 ' and ' $8 \sim 9$ '

The situation ' 7 ' (dollar is a key) is held true, so Contents ' $8-9$ ' (effect of bad influence) is true. These satisfy the constraints of the 7th subschema of Background.

Table 2: Attributes of sample sentences

\begin{tabular}{|c|c|c|c|}
\hline No. & Type & Time & Modality \\
\hline 1 & Durative & Before & $\mathrm{M}-e p_{c v i}$ \\
\hline 2 & Non-repetitive & Before & M-epewi \\
\hline 3 & Static & Simult. & $\mathrm{M}-d e_{e v t}, \mathrm{M}-e p_{c o n}$ \\
\hline 4 & Static & Simult. & $\mathrm{M}-c p_{\mathrm{con}}$ \\
\hline 5 & Durative & Alter & M-ep con \\
\hline 6 & Non-repetilive & After & M-dedir \\
\hline 7 & Static & Simult. & $\mathrm{M}-\epsilon p_{c o n}$ \\
\hline 8 & Non-jepetitive & After & M-ep $a s m$ \\
\hline 9 & Durative & After & M-ep con \\
\hline 10 & Durative & Alter & $M-d e_{r e q}$ \\
\hline
\end{tabular}




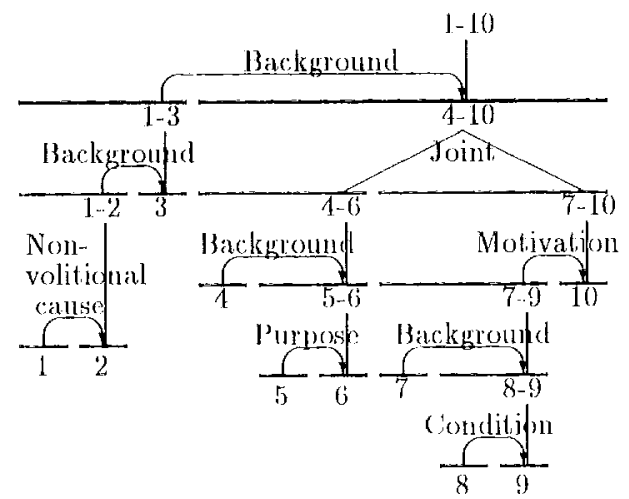

Figure 2: Discourse structure of the sample text

- Motivation(2) between '7.9' and '10'

Sentence '7-9' states a bad situation (eflect ol bad inlluence), and the action in '10' (re-solidify their cooperation) has the possibility to change the situation. 'The writer is requesting the other comutrios to take this action. 'These satisly the constraintis of the 2nd subschema of Motivation.

- Background(9) between '1-3' and '1-10'

'The request in ' $4-10$ ' (re-solidify their cooperation) is based on the judgenent of ' $1-3$ ' (a writer's cvaluation of the economic crisis). 'These satisfy the constraints of the gh subschema of Background.

\section{Conclusion}

In this paper, we propose further a loreakdown of the presentational relations in RST into their subschemas. The suloschenas represent strategies by which two states/actions/events which stand in certain semantic relationships can be used to atain intended effects on readers. By ansocialing the definitions of the relations with formally stated constraints, these subsclicmas holp human analysts to recognise them in texts, and thus improve RST as an analytical tool. Moreover, because characterisation of clauses in Section 3, especially Modality and Lense/Aspect, are accompanied hy their actual linguistic realisations, some parts of the constraints stated in Section 4 can readily be associated with textual forms and be used for text processing systems. Although constraints on semantic relations betwen (Sontents can only be evaluated by reference to a knowledge base, we expect that, even without constrantis on semantic relations, the other constraints can be used to restrict a set of possible inter-clatisal structures of texts.

We have defined four presentational relations in RST more formally and analysed a sample text using these definitions. But the definitions do not cover all the relations in RS'T and have not been widely tested. After defining all the relations, wo will apply them to analyse? a full range of text

\section{References}

Ilalliday, M. A. K. and Masan, R. (1985) Language, contexl, and lext: aspects of language in a socialsemiolic perspective. Oxford University Press.

Ilovy, L, Lavid, J, Maice, F., Midal, V., and Paris, C. (1992). Jimploying knowled ge resourees in a now text planner atchitecture In Proe of oth Internalional Workshop on NLCi, p), 57-72.

Linden, K. V., Cumming, S., and Martin, J. (1992) Using system networks to build rletorical structures. In Proc of oth International Workstopo on NhCi, pls. $18.3 \cdots 198$.

Mann, W. C. and Thomeson, S. A. (1987). Rhetorical structure theory: A theory ol text organization. USC:LSI Reprint Sories RS-87-190.

Moore, J. D. and Pollack, M. li. (1992). A problem for RS'l: The need for multi-level discourso malysis. Compulational himguisties, 18(4), pp. 537544.

Palmer, F. R. (1986). Mood and modality. Cambridge: University Press.

Bösner, D) and s'tede, M. (1992). ('ustonning RS'l" for the automatic production of technicat mannals In Proc of 6th Intcrnational Workshop on NLG, Pl. 199211 